\title{
A AFIRMAÇÃO DO TRABALHO FEMININO NA TRAJETÓRIA HISTÓRICO-CULTURAL DE VILA BOA DE GOIÁS: UMA PERSPECTIVA PARA O PLANEJAMENTO TURÍSTICO
}

\author{
THE STATEMENT OF WOMEN WORK IN THE HISTORICAL AND \\ CULTURAL TRAJECTORY OF VILA BOA DE GOIÁS: A PERSPECTIVE \\ FOR TOURISM PLANNING
}

\section{LA AFIRMACIÓN DEL TRABAJO FEMENINO EN LA TRAYECTORIA HISTORICA Y CULTURAL DE VILA BOA DE GOIÁS: UNA PERSPECTIVA PARA LA PLANIFICACIÓN DEL TURISMO}

\author{
Luana Nunes Martins - Universidade Federal de Goiás - Goiânia - Goiás - Brasil \\ luanunes_7@hotmail.com \\ Ana Paula Fernandes Lopes de Souza - Instituto Federal de Educação, Ciência e Tecnologia \\ de Goiás - Goiânia - Goiás - Brasil \\ anapaulafl@pop.com.br \\ Gilda Guimarães - Universidade Federal de Goiás - Goiânia - Goiás - Brasil \\ gildag@ifgo.edu.br
}

\begin{abstract}
Resumo
0 artigo apresenta-se originalmente como resumo de Trabalho de Conclusão do Curso Tecnológico de Gestão Turística, do Instituto Federal de Educação, Ciência e Tecnologia de Goiás. A proposta dessa pesquisa esteve centrada no estudo sobre o trabalho das mulheres da cidade de Vila Boa de Goiás, visto da perspectiva social do trabalho feminino da poetisa Cora Coralina. A pesquisa analisou a construção histórica e identitária desse trabalho ao longo dos anos. É resultado da investigação teórica e documental de escritos da poetisa, de fontes bibliográficas nacionais e estrangeiras abordando as questões de gênero, da revisão bibliográfica sobre a história de Goiás e, por fim, da realização da pesquisa de campo na própria localidade. 0 resgate e análise da obra literária de Cora Coralina e os depoimentos de mulheres da cidade dão consistência ao sentido do trabalho feminino em Vila Boa de Goiás. Esse sentido de trabalho feminino foi apropriado pela pesquisa como elemento potencializador da atividade turística de caráter histórico-cultural da óptica da sustentabilidade.
\end{abstract}

Palavras-chave: trabalho feminino, Vila Boa de Goiás, turismo, Cora Coralina.

\section{Abstract}

The article is originally presented as a summary of Work Concluded of the Course in Tourism Management of the Federal Institute of Education, Science and Technology of Goiás. The proposal that this research developed was centered in the study about the women's work in the city of Vila Boa de Goiás, under the Cora Coralina social perspective of the feminine work. The research analised the history construction and the identity of this work along the years. It's the result of the theoretical and documental investigation of the poet's written, national bibliography and foreign sources boarding the genus's questions, of the bibliographic revision about Goiás history and finally, the acchivement of the research in the local city. The rasom and analysis of Cora Coralina's literature work and depositions of the women of the city give consistence to the meaning of feminine work in Vila Boa de Goiás. This meaning of feminine work was appropriate by the research as a potential element of the touristic activity of cultural and history character under the view of sustentability.

Key words: feminine work, Vila Boa de Goiás, tourism, Cora Coralina. 


\section{Resumen}

El artículo fue originalmente presentado como un resumen de Trabajo de Conclusión del Curso de Gestión Turística del Insituto de Educación, Ciencia y Tecnología de Goiás. La propuesta que ésa investigación desarrolló se centró en el estúdio acerca del trabajo de las mujeres de Vila Boa de Goiás, bajo la perspectiva social del trabajo femenino de la poetisa Cora Coralina. La investigación examinó la construcción historica y la identidad de ése trabajo a lo largo de los años. Es el resultado de la pesquisa teórica y documental de escritos de la poetisa, de fuentes biblioráficas nacionais y extranjeras abordando las cuestiones de género, la literatura sobre la historia de Goiás y, finalmente, da realización de la pesquisa de campo en su propia localidad. La recuperación y análisis de la obra literaria de Cora Coralina y los testimonios de mujeres de la ciudad dan consistencia al sentido del trabajo femenino em Vila Boa de Goiás. Ése sentido del trabajo femenino fue apropiado por la pesquisa como un elemento potenciador de la actividad turística de carácter histórico y cultural en la óptica de la sostenibilidad. Palabras clave: trabajo femenino, Vila Boa de Goiás, turismo, Cora Coralina.

\section{Considerações iniciais}

No contexto atual da economia, o turismo se depara com duas possibilidades distintas: (1) promover-se como uma proposta econômica de inclusão social e contribuir com novas perspectivas de valorização da vida, do usufruto de produtos culturais e de distribuição de renda; e (2) associar-se a uma economia de mercado que exclui parcelas significativas da população de participarem do crescimento econômico e social.

O turismo apropria-se principalmente do espaço geográfico como objeto de consumo, influindo nas mais variadas relações e transformações socioespaciais de uma cidade. Como foco deste estudo, apresenta-se a Cidade de Goiás, importante núcleo urbano desde o período da mineração aurífera do estado de Goiás, no Centro-Oeste brasileiro.

De acordo com Silva (2001), a Cidade de Goiás, Patrimônio Histórico da Humanidade desde 27 de junho de 2001, título conferido pela Unesco, conserva mais de $80 \%$ de sua arquitetura barroco-colonial original, situando-se em um belo cenário topográfico e atraindo milhares de turistas todos os anos em razão de seus museus, casarios, igrejas, palácios, becos e ruas, além da Serra Dourada e uma vegetação cerradeira abundante. A cidade é conhecida também por sua tradicional Procissão do Fogaréu e pela criação, no final dos anos 90, do Festival Internacional de Cinema e Vídeo Ambiental (Fica).

Novas formas de ação na gestão de bens culturais surgem todos os dias quando se procura articular o patrimônio cultural ao turismo. Infelizmente, nem todas essas ações têm como objetivo a inclusão da comunidade local, que preservou e guardou o bem histórico, utilizando-o como estratégia para a melhoria da qualidade de vida a partir da comercialização sustentável desse bem patrimonial. 
A presente pesquisa buscou apresentar o universo feminino da Cidade de Goiás, onde mulheres, embora ausentes na documentação oficial, participaram e participam da construção da memória identitária da cidade e do estado, preservando e cultivando até os dias de hoje as tradições locais, como um princípio de vida que rege seu trabalho. E esse mesmo trabalho, hoje imprescindível para o desenvolvimento da Cidade de Goiás, principalmente em relação à sua atratividade turística, ainda possui pouca visibilidade social, histórica e cultural.

\section{A trajetória histórica do trabalho e da participação feminina}

A carência de fontes diretas constitui um meio de ocultamento e exclusão da presença das mulheres no percurso da História, em relação à vida e ao espaço público, o que denota a pouca visibilidade de sua contribuição para a esfera produtiva e da articulação do seu trabalho extradomiciliar com o trabalho doméstico.

Formulações que refletem a inferioridade da mulher, sua incapacidade intelectual e a sua associação à perversão do homem perduraram na história e atingiram a visão dos legisladores civis e da Igreja, além de darem origem a pontos de vistas que até nos tempos mais modernos permanecem latentes. As mulheres, estigmatizadas pela inferioridade que sempre as restringiram de direitos igualitários, foram diferenciadas em todos os aspectos possíveis, na educação e formação recebidas, na liberdade religiosa e civil, no matrimônio e fidelidade conjugal, mas, sobretudo, em relação ao trabalho.

De acordo com Soihet (2001), com a urbanização do Brasil, durante o século XIX, a mulher de origem social proletária foi inserida na nova ordem que então se instaurava, contribuindo em grande escala com a consecução dos propósitos da sociedade capitalista que se formava. Entretanto, a lista dos trabalhos de mulheres é codificada, limitada e apresentada por meio de arquétipos do tipo: remendeira, rendeira, trabalhos voltados à repetição e que só podem reproduzir a imagem feminina. Segundo Fonseca (2001), estavam reservadas às mulheres as tarefas menos especializadas e mal remuneradas, onde era total a falta de higiene e segurança e controle disciplinar muito rígido, além dos assédios sexuais que eram constantes.

O movimento feminista culminou nos anos 60 e abalou o mundo ocidental, sendo responsável em larga escala pela visão e aceitação mais democrática do trabalho feminino. 
Para Perrot (1988, p. 212), “as mulheres não são passivas nem submissas. A miséria, a opressão, a dominação, por reais que sejam não bastam para contar sua história”. E na História da formação do país é possível perceber a presença inevitável do trabalho feminino, nos povoados coloniais, onde tudo começou, e na construção da sociedade moderna, que ele influenciou em grande medida. Segundo Giulani (2001, p. 644), "desde a Colônia temos vozes femininas que preconizam a Abolição dos escravos, a instauração da República, a introdução do sufrágio universal”.

\section{A história do trabalho feminino no contexto histórico da Cidade de Goiás}

Em Goiás, do início de sua ocupação pela exploração nas Minas de Goyases à estruturação do Arraial de Sant’Anna, cujo espaço urbano foi denominado mais tarde de Vila Boa de Goiás, encontra-se a força da resistência feminina e a persistente capacidade de definir novos papéis para si, em atitudes de luta cotidiana pela ampliação dos espaços de sobrevivência.

Bartolomeu Bueno da Silva, o Anhanguera, foi o primeiro a chegar nas terras goianas. Com a intenção de se fixar na região, após uma viagem com muitas dificuldades, encontrou ouro na cabeceira do Rio Vermelho, na atual Cidade de Goiás. Segundo Palacín (1994), esta foi a primeira região ocupada no estado de Goiás, onde foi fundado o Arraial de Sant'Ana, que se chamaria posteriormente Vila Boa de Goiás e, por último, Cidade de Goiás. Esse território foi elevado pela corte portuguesa à condição de Capitania em 1749 e seu primeiro governador foi D. Marcos Noronha, o Conde dos Arcos.

A sociedade colonial goiana era formada por uma diferença marcante entre homens livres e escravos. No contexto brasileiro, a economia açucareira dominante nos dois primeiros séculos de colonização foi estruturada sobre o trabalho escravo. E com a mineração não foi diferente.

De acordo com Saint-Hilaire (1975), a ocupação do território não foi muito pacífica, uma vez que os aventureiros eram atacados pelos índios Caiapó. Em muitos casos, forçava-os a abandonar seus postos.

Entre esses índios, diz Saint-Hilaire, as mulheres eram responsáveis pelas coletas (sejam de lenhas ou de mandubes - amendoins), carregando fardos nas costas, amarrados em uma alça atada à testa com comprimento até a altura das pernas. Da mesma forma carregavam os filhos, a fim de deixar os braços livres para trabalhar. 
Mawe (1978) afirma que durante a extração do ouro os homens negros realizavam o trabalho mais penoso, enquanto as mulheres eram responsáveis por carregar o cascalho retirado em gamelas para a lavagem. Britto (1982) ainda relata que, além de ajudar na lavoura, as mulheres também faziam deveres de mucama na Casa Grande, dedicadas aos serviços domésticos de cuidado e limpeza das propriedades senhoriais, amamentação e cuidados da prole dos seus senhores. Eram exploradas, afastadas de seus entes, açoitadas, obrigadas às vezes a se prostituir nas vilas. Documentos mostram que, quando o homem não podia ter filhos com sua esposa, os tinha com escravas, o que para Falci (2001, p. 248), "remete à noção da coisificação da escrava. [...] Os filhos eram dele em uma e não com uma escrava”.

Del Priore (2001) afirma que, na colônia, o casamento significava para a mulher um equilíbrio social, ausência de paixões, obediência e subordinação. Pelo menos essa era a visão da sociedade sobre aquelas que se casavam. Mawe (1978) informa que nesse período existia a proporção de uma mulher para cada trinta e cinco homens e, para que tivesse direito de propriedade da terra, faziam-se exigências a elas além das que eram feitas habitualmente aos homens.

A mulher branca da colônia, porém da classe mais pobre, também sofreu com os ditames da sociedade colonial. Venâncio (2001) registra o sofrimento das mulheres para trabalhar ou manter o sonho de se casar, as duras normas do pai, do esposo, da igreja e da sociedade com relação à sexualidade, o preconceito com relação à condição de mãe solteira e a difícil luta para sua inserção social. Muitas mulheres tiveram necessidade de abandonar os próprios filhos. Venâncio (2001, p. 190) afirma que "a história do abandono de crianças é a história secreta da dor feminina”.

No início do século XIX, as mulheres permaneciam excluídas de qualquer exercício de função política nas câmaras municipais e na administração eclesiástica, além de também proibidas de ocupar cargos da administração colonial com reconhecimento social. Apareciam ocupadas na panificação, tecelagem, alfaiataria, além de funções exclusivas como costureiras, doceiras, fiandeiras, rendeiras, cozinheiras, lavadeiras ou criadas, atividades em geral reservadas a elas. Algumas exerciam a função de parteiras, apresentando "cartas de exame" dadas por médicos para comprovar a aptidão ao exercício legal da função. Para Mattos (1832), a tecelagem doméstica no interior é uma continuidade dos afazeres da casa, 
onde as mulheres cuidavam da família, da cozinha e do artesanato de subsistência, já que toda casa tinha um tear.

Após a transferência da capital para Goiânia, com a chamada Marcha para o Oeste e a transição do rural para o urbano, cresceu a participação e inserção da mulher na história do estado. Anteriormente a esse processo, já existiam mulheres que contestavam e formavam uma classe de luta e resistência, mas ainda havia repressão da sociedade, majoritariamente machista.

Britto (1982) registra a presença de algumas mulheres que se destacaram na sociedade local à época em que viveram, como Damiana da Cunha (1779-1837), indígena educada na cultura dos brancos e casada com sargento, que assumiu a liderança na resistência cultural Caiapó. A Escrava Rosa foi propriedade de diversos donos enquanto cativa; viveu mais de cem anos, sofreu, trabalhou e deu filhos à Cidade de Goiás, sem mencionar suas intenções políticas de inserir o negro como ser humano, mas morreu sem ver a instauração da Lei Eusébio de Queirós, Lei do Ventre Livre, Lei dos Sexagenários e a Lei Áurea.

Britto (1982) ainda relata a atuação de outras mulheres educadoras, poetisas, atrizes, musicistas, que se destacaram no âmbito da igreja pela criatividade e ousadia, jornalistas, políticas, "santas" e precursoras do feminismo. Entre elas: Maria Romana da Purificação (1800-1873); Pacífica Josefina de Castro (1846-1932); Ana Xavier de Barros Tocantins (1857-1949); Augusta de Faro Fleury Curado (1865-1929); Maria Angélica da Costa Brandão, a “Nhanhá do Couto” (1880-1945); Eurydice Natal e Silva (1883-1970); Alice Augusta de Sant'Anna (1884-1963); Oscarlina Alves Pinto (1885-1949); Maria Henriqueta Peclat (1886-1965); Amélia Brandão (1898-1983); Célia Coutinho Seixo de Brito (1914-1994); Ida Artiaga Moreno (1915); Florany Pinheiro (1927-1988); Belkiss Spencière Carneiro de Mendonça (1928-2005); Silvina Hermelinda Xavier de Brito (1835-1920); Rose Pelagie Boissié, a "Irmã Rosa Sant'Anna” (1870-1941); Augusta Sócrates Gomes Pinto (1879-1965); Josefina Pinheiro de Lemos Mendes (1891-1971).

Rocha e Bicalho (1999) informam que no início do século XX teve lugar a luta pelo voto e participação feminina na industrialização. A década de 1980 ficou marcada pelas ações contra os abusos dos patrões, direito a licença maternidade, criação de creches, acesso à educação comum, inclusão em profissões especializadas, combate à discriminação da mulher negra, formação de grupos de estudos sobre o gênero feminino. Iniciou-se também a criação de entidades feministas em Goiás, como o Centro de 
Valorização da Mulher (Cevam), criado em 1981 e o Centro Popular da Mulher (CPM), criado em 1985. Nessa década também as mulheres goianas participaram ativamente da luta em entidades sindicais tanto urbanas como rurais, em movimentos sociais e no cenário político.

\section{Cora Coralina: imagem do trabalho feminino refletido em sua trajetória de vida e produção literária}

Ana Lins dos Guimarães Peixoto Bretãs (1889-1985), conhecida como Cora Coralina, nasceu e viveu em Vila Boa de Goiás. Identificou-se com as realidades humanas, enfocando a dinâmica das pessoas no lugar público, destacando em suas obras e em sua própria vivência o trabalho da mulher e englobando tanto a participação na produção social como o trabalho reprodutivo exercido no espaço privado da família. Desvencilhou-se de todo tipo de discriminação e não negou sua condição de mulher, aceitando até os fardos mais pesados dessa condição para sua época. Referia-se ao trabalho (gleba) como algo que a transfigurasse, ou seja, o trabalho como fator de transformação social.

Cora Coralina expôs a figura feminina com a sensibilidade de quem havia experimentado a vida simples e a esta declarava louvor, especialmente quando, mesmo consciente de sua vocação filosófica por meio da poesia, afirma: "Fiz um nome bonito de doceira, minha glória maior". Em um de seus poemas ainda diz que nada mais pretendia ser além de trabalhadora, "mulher primária, roceira, operária, afeita à cozinha, ao curral, ao coalho, ao barreleiro, ao tacho" (Coralina, 1987, p. 27). No poema "Todas as Vidas” (Coralina, 2004, p. 253) é possível perceber mais profundamente sua identificação com a condição feminina de realização pelo trabalho.

TODAS AS VIDAS

Vive dentro de mim

uma cabocla velha

de mau-olhado,

acocorada ao pé do borralho,

olhando pra o fogo.

Benze quebranto.

Bota feitiço...

Ogum. Orixá. 
Macumba, terreiro.

Ogã, pai-de-santo...

Vive dentro de mim

a lavadeira do Rio Vermelho.

Seu cheiro gostoso

d’água e sabão.

Rodilha de pano.

Trouxa de roupa,

pedra de anil.

Sua coroa verde de são-caetano.

Vive dentro de mim

a mulher cozinheira.

Pimenta e cebola.

Quitute bem feito.

Panela de barro.

Taipa de lenha.

Cozinha antiga

toda pretinha.

Bem cacheada de picumã.

Pedra pontuda.

Cumbuco de coco.

Pisando alho-sal.

Vive dentro de mim

a mulher do povo.

Bem proletária.

Bem linguaruda,

desabusada, sem preconceitos,

de casca-grossa,

de chinelinha,

e filharada.

Vive dentro de mim

a mulher roceira.

- Enxerto da terra,

meio casmurra.

Trabalhadeira.

Madrugadeira. 
Analfabeta.

De pé no chão.

Bem parideira.

Bem criadeira.

Seus doze filhos,

Seus vinte netos.

Vive dentro de mim

a mulher da vida.

Minha irmãzinha...

tão desprezada,

tão murmurada...

Fingindo alegre seu triste fado.

Todas as vidas dentro de mim.

Na minha vida -

a vida mera das obscuras.

No trecho "Todas as vidas dentro de mim. / Na minha vida - / a vida mera das obscuras”, Cora fazia alusão à condição feminina de exercício do papel secundário e sem importância na sociedade, cujo trabalho e a própria existência eram ignorados ou desconhecidos, daí o termo "obscuras".

Cora Coralina estava familiarizada ao ambiente doméstico, onde normalmente não se cultivava a leitura. Os preconceitos que exigiam submissão a padrões inflexíveis, em muitos casos, tornavam a mulher inculta e rude: "As mulheres do passado não sabendo ser carinhosas / que aquele tempo de dureza e severidade não ajudava / tornavam-se cruéis" (1987, p. 7). A poetisa ateve-se também às dificuldades enfrentadas pelas mulheres trabalhadoras de sua época e retratava constantemente seu cotidiano de trabalho, opressão e submissão, sem deixar de assumir a grandeza de seu lugar na sociedade.

[...] A pobreza em toda volta, a luta obscura de todas as mulheres goianas.

No pilão, no tacho, fundindo velas de sebo, no ferro de brasas de engomar. Aceso sempre o forno de barro.

As quitandas de salvação, carreando pelos taboleiros os abençoados vinténs, tão valedores, indispensáveis.

Eram as costuras trabalhadas, os desfiados, os crivos pacientes. 
A reforma do velho, o aproveitamento dos retalhos.

Os bordados caprichados, os remendos instituídos, os cerzidos pacientes.

Tudo economizado, aproveitado. [...]

(Coralina, 1957, p. 54)

A poetisa preocupava-se com o novo pensamento que se inseria na sociedade e manifestava-se na atitude de muitas mulheres, principalmente aquelas que trabalhavam fora deixando seus filhos em creches ainda muito pequenos. Isso não significa que era a favor de qualquer repressão ou falta de liberdade do gênero; pelo contrário, apelava para que a mulher não permitisse que as mudanças socioculturais fizessem com que ela negasse seu verdadeiro papel de mulher. Cora argumentava ainda que, ao tentar se igualar ao homem em condições de trabalho, a mulher estaria acarretando sofrimento para si mesma, sobrecarregando-se.

Renovadora e reveladora do mundo

A humanidade se renova no teu ventre

Cria teus filhos, não os entregue à creche.

Creche é fria, impessoal.

[...] Que pretendes, mulher?

Independência, igualdade de condições...

Empregos fora do lar?

És superior àqueles que procuras imitar.

Tens o dom divino de ser mãe.

Em ti está presente a humanidade.

(Coralina, 1987, p. 171)

Cora avançou para o espaço público, antes reservado apenas aos homens, sem sair do espaço privado, reservado somente às mulheres, fazendo da conquista da palavra escrita importante capital cultural na luta de resistência social à exclusão.

A análise de sua trajetória, mostrando seu processo de inserção no campo literário brasileiro e a forma de vida simples pela qual optou, fornece elementos significativos para a compreensão das influências e posicionamentos que assumiu perante as questões de seu tempo e de sua terra. Ao mesmo tempo, suas produções permitem reconstituir as características gerais da sociedade com a qual conviveu tão de perto. 
A presença do trabalho feminino na Cidade de Goiás hoje e a autoimagem do trabalho, condição feminina e condição identitária histórica e cultural

Na esfera pública da cidade, pode-se constatar que as mulheres constituem a maioria atuante, principalmente nos campos da educação e saúde, tendo também ocupação significativa nos cargos da administração pública. Um exemplo são os projetos sociais desenvolvidos à época da pesquisa pela primeira dama do município Rita Curado, como o "Conviver", para beneficiar moradores de mais de sessenta anos com o acesso a programas culturais e de lazer, e a "Casa do Doce", que comercializa, em consignação, produtos de doceiras da cidade.

No comércio da cidade é também possível observar a grande participação feminina. As mulheres conciliam seu trabalho doméstico com empregos em lojas e feiras (artesanato, vestuário, artigos de festas, entre outros), bares, restaurantes e lanchonetes, salões de beleza, mercados e pousadas. Muitas delas, principalmente mulheres aposentadas ou que não trabalham fora, criaram seu comércio em sua própria residência. Ocupam-se na venda de doces cristalizados, licores, artesanatos típicos da cidade, costuras e até mesmo transformando suas residências em pousadas para hospedar turistas em altas temporadas.

O trabalho dessas mulheres revela uma conexão com o contexto sociocultural da Cidade de Goiás e de seu entorno: a região do cerrado. Os aspectos dessa conexão podem ser extraídos da história dessas mulheres, das formas de criação, produção e circulação de seus produtos e da maneira como elas os percebem como trabalho e manifestações artísticas.

Para Chaud e Guimarães (2005, p. 12),

isto é um reflexo de uma espécie de resistência que, geralmente, as mulheres lançam mão para buscarem formas de manutenção a fim de superarem dificuldades e romperem barreiras como a pobreza e os preconceitos impostos à mulher na sociedade. Mas, também, traduz uma vontade, uma busca de aprender, de sair de um lugar para outro, de uma condição para outra. Revela um diálogo com algo maior, mais forte, algo que organiza a vida. Onde vão buscar esse conhecimento? No rol de saberes familiares [...].

A tradição das doceiras da Cidade de Goiás é antiga, mas consolidou-se e passou a agregar valor cultural a partir da representação de Cora Coralina, que chegou a escrever sobre esse trabalho que a sustentou por anos. 
As quituteiras costumam trabalhar em casa, onde também recebem os turistas. Suas especialidades são os doces cristalizados, como o cajuzinho do cerrado, feitos no tacho de cobre com ingredientes locais.

Uma das doceiras mais antigas de Goiás, que trabalhou com Cora Coralina por 14 anos, ainda tem como importante fonte de renda a venda de seus doces, principalmente para turistas que sempre a visitam. Em entrevista, diz:

Eu costumo falar que a Dona Cora morreu e deixou um presente pra Cidade de Goiás. [...] Hoje todo mundo tem seu jeito de ganhar dinheiro. Uma é salgadeira, a outra mexe com artesanato, a outra é doceira, mas tem que ter. Foi ela quem fez abertura, né? [...] A pessoa que antes não tinha valor em nada, não tinha nada pra fazer... Antes era só casa e marido, agora não, todo mundo tem seu dinheirinho.

Na cidade observa-se ainda um número expressivo de mulheres voltadas para o artesanato ceramista e para a confecção de artefatos que vão da roupa de vestir às colchas, bonecas, tapetes, almofadas e bolsas, materiais que são colocados à venda nas feiras e lojas de artesanato da cidade. O trabalho manual realizado com habilidade, seja moldando cerâmicas, seja tecendo tapetes e rendas, bordando ou entalhando a madeira, mostra que a sensibilidade da artesã acompanha sua criação.

As costureiras caseiras ainda existem em abundância pela cidade. Elas trabalham com tecidos e confeccionam roupas, fantasias e indumentárias que fazem parte dos costumes regionais. Uma delas, em entrevista, enfatiza a importância de seu trabalho como terapia e como força organizadora de sua vida: "Foi minha mãe que começou assim, mexer com cocha, né, e... tô aí agarrada nas cochas, forro, tapete [...]. Esse trabalho meu faz parte da história de Goiás porque é um trem dos antigo, da época de Cora $[. .]$.$" .$

O artesanato de argila da Cidade de Goiás recebeu forte influência indígena, consistindo principalmente na manufatura de utensílios domésticos como potes, panelas, buiões e também peças artesanais inovadoras. É um bem cultural que, além de contribuir para a geração de renda de centenas de famílias, promove o potencial turístico.

Segundo relatos extraídos do documentário "Na ponta dos dedos Criatividade e Cooperativismo", da Associação dos Artesãos de Goiás, o artesanato local vinha perdendo sua autenticidade e originalidade como traço cultural do povo goiano por causa da forte solicitação de um merca- 
Artigo

do urbano para atender o comprador intermediário que levou as peças a serem produzidas no torno e vendidas por preços irrisórios.

Como solução para o problema, foi proposta a organização de uma associação com todos os artesãos e, a partir daí, surgiu a associação, criada como um sistema cooperativo e comunitário. Muitas pessoas foram beneficiadas, encontrando meios para a realização de seus trabalhos e para a exposição do produto, conforme consta do depoimento de uma artesã, extraído do documentário: "Para mim eu achei muito bom demais fazer, é melhor do que se eu estivesse trabalhando de doméstica [...] é uma profissão que eu tenho agora. Melhorou muito minha vida” (Documentário, 1998).

Outro depoimento de uma artesã da associação, retirado do mesmo documentário, evidencia que o trabalho delas está integrado às suas vidas, e o que elas fazem possui ligação com a história e a memória de cada uma. Elas o sentem como algo necessário: “A mamãe fazia e com ela nós foi aprendendo, olhando ela trabalhar [...]. Eu tenho orgulho desse serviço [...]. Um serviço que eu sei que num é dos novo de agora, num é dos cidadão de agora, é um serviço dos antigo, serviço que veio de vó, de minha avó, de minha mãe".

De acordo com Chaud e Guimarães (2005, p. 4), para as mulheres vilaboenses, "fazer artesanato é algo valoroso, digno como qualquer outro trabalho, [...] onde o querer aprender, o inovar, demonstra o diferencial dos trabalhos destas mulheres".

Goiandira do Couto, nascida em 1915, artista plástica, reconhecida em âmbito mundial, teve a sua pintura dividida em duas fases: a fase do óleo (1933-1967) e a fase da pintura com areia (iniciada em 1968). Criadora da técnica da pintura com areia, possui atualmente mais de 550 tonalidades de areias retiradas apenas da Serra Dourada, na Cidade de Goiás, onde reside desde os seis anos de idade e de onde confessa vir a inspiração de suas obras pela beleza, romantismo e a natureza sempre presente em cada cantinho dela. Em entrevista, diz:

Ligo meu trabalho à história da cidade porque é o único no mundo... de onde que tira essas areias? Do lugar Serra Dourada, e a serra fica aqui na cidade, foi da pedra goiana. [...] E minha cultura também, minha temática é mais é Cidade de Goiás. E a cidade é muito bonita, dá uma graça, um sabor gostoso, fica lindo, então eu sou mais ligada a Goiás. 
Num artigo que escreveu sobre o roteiro "Encantos dos Saberes e Café com Por-do-Sol”, do projeto "Cidade de Goiás: um baú na ponta do arco-íris", Simões (2006) afirma que "a convivência com os moradores da terra de Cora Coralina é um dos diferenciais que marcam a nova fase do turismo da Cidade de Goiás”. Trata-se de um roteiro lançado pelo Serviço Brasileiro de Apoio às Micro e Pequenas Empresas (Sebrae) e pelo Instituto de Hospitalidade (IH) por meio do Projeto de Desenvolvimento do Turismo, que envolve seis casas que recebem turistas como se fossem visitas da família. O subproduto desse roteiro, chamado "Lá em casa tem", desdobra-se conforme a especialidade de seus moradores, que vão da produção de artesanato a guloseimas regionais. A casa de Sílvia Curado é a atração do "Lá em casa tem alfenim"; outro programa é o "Lá em casa tem doce da vovó", envolvendo quatro casas. No "Lá em casa tem artesanato”, quatro residências envolvendo trinta artesãos recebem visitantes que acompanham a produção das peças de cerâmica, podendo até participar do processo.

Para muitas mulheres da cidade, principalmente as que estão diretamente envolvidas com o turismo, esses projetos dão contribuição significativa para o desenvolvimento e perpetuação de seu trabalho, por meio da ministração de cursos de artesanato, palestras de incentivo e aperfeiçoamento nos setores de hospedagem e guia de turismo. Falando sobre o programa, uma artesã diz em entrevista:

Antes de Goiás ganhar o título, nós não era tachada como artesã, era como paneleira, não era? A pessoa chegava: "Onde que mora Dona Fulana paneleira?” Não era artesã, artesã foi depois de Goiás ganhar o título, que o Sebrae começou a trabalhar aquela idéia [...]. A História de Goiás tá embasada no povo da cidade [...]. Tá tão embasada que eu, hoje eu escrevo também, e eu conto sempre nas minhas poesias [...] eu conto história de pegar barro no barreiro, eu conto a história do Rio Vermelho, que eu fui criada aqui, né [...]. Então eu acho que a história da Cidade de Goiás, é o povo que fez a história [...]

Segundo Meneses (2004), é importante refletir sobre formas de interpretação da cultura como patrimônio para uso turístico, permitindo problematizar o passado, contribuir com o conhecimento e fazer dessa reflexão instrumento de inclusão social.

Pensar no patrimônio cultural da Cidade de Goiás é pensar em sua própria sociedade e problematizar sua existência e sua forma de participa- 
ção na vida. De acordo com esse autor, para que haja a sustentabilidade desse patrimônio é necessário associar sua interpretação ao fazer cotidiano e à vivência da sociedade em questão que construiu e guardou o patrimônio cultural e não dissociar a interpretação da identidade, das idiossincrasias, das tradições e das formas de expressão da sociedade local.

\section{Considerações finais}

É possível perceber que a conceituação de sustentabilidade defendida por Meneses não é apreendida na sua extensão por segmentos responsáveis pela proposição de políticas públicas e pelo planejamento urbano. É notável a falta de subsídios para a consolidação de projetos que deem continuidade ao trabalho de valor histórico e cultural desempenhado por muitas mulheres. Isso se reflete na falta de incentivos para exportação e na pouca visibilidade de sua importância social e histórica pela população e administradores locais.

A Cidade de Goiás está construindo uma alternativa de desenvolvimento por meio do turismo. Grande parte das pessoas envolvidas nesse processo são mulheres que atendem aos turistas direta ou indiretamente. O trabalho realizado por elas atrai não só a curiosidade, mas também o anseio por compreender a história da formação da sociedade goiana, visto que esse trabalho está carregado de peculiaridades trazidas do passado.

De acordo ainda com Meneses (2004), para que haja perspectiva de um planejamento turístico que explore de maneira sustentável um atrativo, como o referido acima, faz-se necessário a integração entre os bens patrimoniais, a população que os constroi e administra e os profissionais que refletem sobre a preservação, no intuito de construir uma intervenção prática reflexiva que possibilite:

- A democratização do conhecimento sobre o patrimônio da comunidade, a orientação e a conscientização sobre esse patrimônio de forma ampliada;

- O gerenciamento do projeto de desenvolvimento focado no bem patrimonial apreendido e a capacitação da comunidade na prestação dos serviços infraestruturais;

- O incentivo ao desenvolvimento da cidade, incluindo parcelas significativas da comunidade na participação desse desenvolvimento econômico; 
- A sensibilização para ações preservacionistas e de promoção da memória histórica local e regional, que também inclua toda a sociedade participante.

Deve-se, sobretudo, desenvolver um processo identitário na Cidade de Goiás, a partir da realidade social de suas peculiaridades e de suas tradições, que se adeque à vivência das pessoas que compõem seu espaço histórico.

Entretanto, esse processo deve ser uma construção intimamente associada à realidade local, que é distinta em cada locus de observação, demandando metodologias próprias e instrumental variável. Daí, a necessidade de reflexão e exercício profissional competente e bem gerenciado. Ações que são empregadas em algumas cidades históricas coloniais poderão não ser as mesmas adotadas na Cidade de Goiás, principalmente no que tange à valorização do trabalho feminino. Além disso, novas pesquisas possibilitarão a análise da trajetória desse trabalho e sua apropriação como meio de desenvolvimento da cidade, bem como aspectos de sua atual condição.

\section{Referências}

BRITTO, Célia Coutinho Seixo de. A mulher, a história e Goiás. Goiânia: Ed. da UFG, 1982.

CHAUD, E.; GUIMARÃES, L. A natureza feminina do cerrado. Goiânia: Max Gráfica \& Editora, 2005.

CORALINA, Cora. Vintém de cobre: meias confissões de Aninha. Goiânia: Ed. da UFG, 1987.

CORALINA, Cora. Melhores poemas/ Cora Coralina. São Paulo: Global, 2004.

DOCUMENTÁRIO na ponta dos dedos - criatividade e cooperativismo. Associação dos Artesãos de Goiás. Direção de Geraldo Morais. Brasília: CPCE/Universidade de Brasília, 1988.

FALCI, Miridan Knox. Mulheres do sertão nordestino In: DEL PRIORE, Mary (Org.); BASSANEZI, Carla (Coord.). História das mulheres no Brasil. São Paulo: Contexto, 2001. p. 241-277.

FONSECA, Cláudia. Ser mulher, mãe e pobre. In: DEL PRIORE, Mary (Org.); ASSANEZI, Carla (Coord.). História das mulheres no Brasil. São Paulo: Contexto, 2001. p. 510-553.

GIULANI, Paola Cappellin. Os movimentos de trabalhadoras e a sociedade brasileira. In: DEL PRIORE, Mary (Org.); BASSANEZI, Carla (Coord.). História das mulheres no Brasil. São Paulo: Contexto, 2001. p. 640-667. 
MATTOS, Raymundo José da Cunha. Memória estatística da província de Goyaz. Rio de Janeiro: Typografia Nacional, 1832.

MAWE, Jonh. Viagens ao interior do Brasil. Belo Horizonte: Itatiaia, 1978.

MENESES, José Newton Coelho. História e turismo cultural. Belo Horizonte: Autêntica, 2004.

PERROT, Michelle. Os excluídos da história: operários, mulheres e prisioneiros. Rio de Janeiro: Paz e Terra, 1988.

PALACÍN, Luis; MORAES, M. A. História de Goiás. Goiânia: Ed. da UCG, 1994.

DEL PRIORE, Mary. Magia e medicina na Colônia. In: . (Org.); BASSANEZI, Carla (Coord.). História das mulheres no Brasil. São Paulo: Contexto, 2001. p. 78-114.

ROCHA, Maria José Pereira; BICALHO, Elizabete (Coord.); FARIA, Gisele Justiniano (Colab.). Luta e resistência de mulheres em Goiás (1930-1993). Goiânia: Ed. da UCG, 1999.

SAINT-HILAIRE, Auguste de. Viagem à província de Goiás. Belo Horizonte: Itatiaia, 1975.

SILVA, Antônio Moreira da. Dossiê de Goiás - enciclopédia regional: um compêndio de informações sobre Goiás, sua história e sua gente. Goiânia: Master Publicidade, 2001.

SIMÕES, Sílvio. Gastronomia e convivência integram novos roteiros em Goiás. [S.l.]: ASN, 2006. Disponível em: http://www.asn.interjonal.com.br/notícia.kmf. Acesso em: 20 mar. 2008.

SOIHET, Rachel. Mulheres pobres e violência no Brasil urbano. In: DEL PRIORE, Mary (Org.); BASSANEZI, Carla (Coord.). História das mulheres no Brasil. São Paulo: Contexto, 2001. p. 362-400.

VENÂNCIO, Renata Pinto. Maternidade negada. In: DEL PRIORE, Mary (Org.); BASSANEZI, Carla (Coord.). História das mulheres no Brasil. São Paulo: Contexto, 2001. p. 189-222.

Luana Nunes Martins - Graduada em Turismo pelo Instituto Federal de Educação, Ciência e Tecnologia de Goiás - IFG - Graduanda em Geografia pela Universidade Federal de Goiás.

Ana Paula Fernandes Lopes de Souza - Graduada em Turismo pelo Instituto Federal de Educação, Ciência e Tecnologia de Goiás - IFG - Pós-Graduação em Docência do Ensino Superior.

Gilda Guimarães - Mestre em Educação - Universidade Federal de Goiás. 